\title{
In silico Identification of Inhibitors from Salacia reticulate Plant against Diabetic Target Protein
}

\author{
D. Ramakrishna, A.T. Shashank, S. Kiran, K.M. Kumar and G.A. Ravishankar* \\ Dr. C.D Sagar Centre for Life Sciences, Biotechnology Department, Dayananda Sagar \\ College of Engineering, Dayananda Sagar Institutions, Kumaraswamy Layout, \\ Bengaluru 560 078, Karnataka, India \\ *Corresponding author
}

A B S T R A C T

\begin{tabular}{|l|}
\hline K e y w o r d s \\
$\begin{array}{l}\text { In silico, Diabetic, } \\
\text { Phytochemicals and } \\
\text { Benzeneacetonitrile, } \\
\text { Alpha.-(.Beta.-D- } \\
\text { Glucopyranosyloxy)-, } \\
\text { (R) }\end{array}$ \\
\hline Article Info \\
\hline $\begin{array}{l}\text { Accepted: } \\
\text { 04 December } 2017 \\
\text { Available Online: } \\
\text { 10 January } 2018\end{array}$ \\
\hline
\end{tabular}

\section{Introduction}

Diabetes is known as $21^{\text {st }}$ century deadly disease and rank $5^{\text {th }}$ place in causing death in developed and developing countries (Kooti et al., 2016). Diabetes is a metabolic disorder due to lack of pancreases function in synthesis of insulin or resistance because of B cells damage. Diabetes occurs majorly from lifestyle i.e. lack exercise, alcoholic, smoke and improper maintains. It is characterized by hyperglycemia and leads to several secondary ill effects in diabetic person (Abirami and Arulmozhi, 2017). Plant based drugs have been used to cure many diseases and play a vital role in drug discovery nowadays. Plant based drugs provide a parental chemical for synthesis many drugs which are available in the market and approved in clinical trials.

Many drugs fail to enter market due to poor pharamacokinetic property may turn huge loss to the companies in drug discovery (NtieKang et al., 2013). Computer aided tools emerged as advanced method in drug discovery and were applied to screen drugs from among phytochemicals found in the medicinal plant against many (Pratibha et al., 
2014). The medicinal plants found in world have health benefits. Many countries consume plant based drug to prevent or eradicate several disease according to WHO. Salacia species available in several countries used mainly in prevent diabetic one such plant is Salciareticulata. Whole plant decoction given orally for inhibits digestive enzymes such as $\alpha$ - amylase and $\alpha$ - glucosides to delays glucose uptake in blood. Salciareticulata plant extract also showed in vivo and in-vitro antidiabetic property (Matsuda et al., 2005). Elicitation of Salcia reticulate plant with biotic $(0.2 \mathrm{mM}$ salicyclic acid) and abiotic (2\% Aspergillus niger) elicitation increase phytochemicals.(Ramakrishna et al., 2018).

Present study was aimed to enhance phytochemicals in the plants through elicitors (biotic and abiotic) and all these phytochemicals were used and molecular screening to analyze their interaction with diabetic enzymes to predict these activity.

\section{Materials and Methods}

\section{Target protein structure preparation}

The crystal structure of targets proteins human cytosolic .Beta.-glucosidase, Crystal Structure of Human SIRT6, Human glucokinase, Sugar beet .Alpha.-glucosidase were selected and retrieved from protein data bank (PDB). The detail of PDB id, protein name and function were listed in Table 1.

\section{Selection of ligands as phytochemicals from GCMS}

All phytochemicals obtained from unpublished data which are derived from GCMS analysis of methanol extract (leaf) with elicitor treated plant. The structure of theses phytochemicals were identified and obtained from pubchem compound database. Canonical smiles were submitted to corina online 3D conversion server to convert $2 \mathrm{D}$ into $3 \mathrm{D}$ structure of phytochemicals. PDB (protein databank) file format was downloaded from corina tool. 3D structure of all phytochemicals was optimized for docking conformation study. The compounds used for optimization were (1) Alpha-D-Glucopyranoside, Methyl 2(Acetylamino)- 2-Deoxy-3-O-(Trime; (2) 1(2-Decylaminoethoxy-2-[2-(2-Trimethyl silyloxyethoxy) Ethoxy]Ethan; (3)Butane, 1,2,3-Tris (Trimethylsiloxy)-;

3,7,11,15,18-Pentaoxa-2,19-Disilaeicosane, 2, 2,19,19-Tetramethyl-; (5) O-Methylisourea; (6) Propanoic Acid, 2-Oxo-, Trimethylsilyl Ester; (7) 1,5,9,9-Tetramethyl-2-Oxatricyclo [6.4.0.0(4,8)] Dodecane; (8) Benzeneacetonitrile, Alpha.-(.Beta.-D-Glucopyranosyloxy)-, (R)-; (9)Trimethyl[4-(1,1,3,3,Tetramethylbutyl) Phenoxy]Silane; Tetracosanoic Acid, Trimethylsilyl Ester; (11) Ala-Gly, Trimethylsilyl Ester; Cyclotrisiloxane, Hexamethyl-;

Eicosanoic Acid 2,3-Bis[(Trimethylsilyl) Oxy] Propyl Ester; (14) 3,27-Dioxa-2,28Disilanonacosane, 2,2,4,28,28-Pentamethyl-; (15) Undecanoic Acid, 11-Fluoro-, Trimethylsilyl Ester; (16) Decanoic Acid, 10Fluoro-, Trimethylsilyl Ester; (17)Oleic Acid, Trimethylsilyl Ester; (18) 17-Octadecynoic Acid, Trimethylsilyl Ester.

\section{Molecular docking}

iGEMDOCK 2.1 was used to study the protein-ligand interaction of the listed GCMS compounds with the $\beta$-glucosidase, SIRT6, glucokinase and $\alpha$-glucosidase target proteins. Initially all the four target proteins and phytocompounds were prepared by assigning hydrogen bonds, bond orders, charges and flexible torsions. The contribution of hydrogen bond energy to the molecular docking score is assigned a penalty based on the deviations from the ideal bonding angle. The structure based molecular docking was done by iGEMDOCKV2.1 offline software (Neem et 
al., 2015). It has been decided to use the following docking parameters for proteinligand interactions such as Population size: 150, Number of generations: 60 and Number of solutions: 2. the customized Docking parameter was selected in setting. In the present study, 18 phytocompounds were selected and imported into gemdock graphical user interface. Phytocompounds were sorted at the post docking analysis based on their binding energies and compound fitness score calculated by iGEMDOCK docking algorithm. Further, the detailed interaction between best phytocompound and four antidiabetic target proteins were analysed in PyMol 3Dimensional (3D) (Lill and Danielson 2010) visualization. Finally, iGEMDOCK ranked compounds and visualized the binding pose of compounds by combining the pharmacological interactions and binding energy-based scoring function [Balavignesh et al., 2013].

\section{Results and Discussion}

The 3D structures of $\beta$-glucosidase, SIRT6, glucokinase and $\alpha$-glucosidaseare analyzed and 18 phytocompounds are optimized to have minimal potential energy. Then the molecular docking study was carried out for phytoligands. From the docking analysis, we predicted binding pose of pytocompounds identified from GCMS analysis based on iGemdock total energy (Table 2). The best binding conformation for each phytocompounds into all four antidiabetic target proteins are determined the one having lowest total binding energy among the different conformation generated. The lowest binding energy scores represent best proteinligand binding stability compared to highest energy score. From the gemdock post docking analysis., Among the 18 phytocompounds, compound 8 Benzeneacetonitrile, .Alpha.(.Beta.-D-Glucopyranosyloxy)-, (R) is found to has lowest binding energy value when compare to all other compounds also shows binding energy similar to that of acarbose standard drug used in this study. Benzeneacetonitrile, .Alpha.-(.Beta.-DGlucopyranosyloxy)-, (R) shows best binding conformation with all four antidiabetic targets proteins $\beta$-glucosidase, SIRT6, glucokinase and $\alpha$-glucosidase (total binding energy score for $\beta$-glucosidase $=-110.7 \mathrm{kcal} / \mathrm{mol}$, SIRT6 = $-108.2 \mathrm{kcal} / \mathrm{mol}$, glucokinase $=-110.4$ $\mathrm{kcal} / \mathrm{mol}, \alpha$-glucosidase $=-116 \mathrm{kcal} / \mathrm{mol})$. The compound_8 Benzeneacetonitrile, .Alpha.(.Beta.-D-Glucopyranosyloxy)-, (R) has formed stable ligand-protein complex amongst other phytocompounds. We further validated the docked conformation for finding the best binding pose of compound_8, Compound_8 into four antidiabetic target proteins to analyse the position obtained likely to represent reasonable binding conformations.

Binding pose of compound 8 into $\beta$ glucosidase, SIRT6, glucokinase and $\alpha$ glucosidase

Post docking process of compound_8 is done for $\beta$-glucosidase, SIRT6, glucokinase and $\alpha$ glucosidase. From the anlaysis, we observe that compound_8 has the best molecular binding affinity with all four anti diabetic target proteins $\beta$-glucosidase, SIRT6, glucokinase and $\alpha$-glucosidase. Molecular docking of compound_8 results in the formation of more than two hydrogen bonds with $\beta$-glucosidase. Amino acid residues TRP345, GLU424 are participated in Hbond interaction with compound_8 (Fig. 1). From the compound_8-SIRT6 complex analysis, we identified five $\mathrm{H}$-bonds are formed between compound_8 and SIRT6. LEU239, GLU20, ASP61, THR55 and GLY52 of SIRT6 are involved in H-bond formation with compound_8 (Fig. 2). In examining the binding interaction and binding position of compound_8 in glucokinase predicted by post docking analysis, it is noted that multiple $\mathrm{H}$ - 
bonds are formed. In addition, the amino acid residues ILE225, ASN204, ASN204, ASN204, THR206 and ASP205 are involved in six H-bond interaction (Fig. 3). From the post docking screening of compound_8 with $\alpha$-glucosidase, it is observed that the amino acid residues ARG699, ARG699, ARG699, THR790, GLU792, ARG814 and GLY791 contributed maximum eight $\mathrm{H}$-bonds with compound_8 (Fig. 4). On comparing all four complexes, compound_8 formed maximum number H-bonds with $\alpha$-glucosidase (Table 3 ).

The detailed binding interaction of compound_with all four anti diabetic target proteins, $\mathrm{H}$-bond length, atoms and amino acid residues involved in binding interaction are shown in Table 2.

Table.1 List of anti-diabetic target proteins and their function

\begin{tabular}{|c|c|c|c|c|}
\hline SI no & Pdb id & Protein name & Protein function & Reference \\
\hline 1 & 2jfe & $\begin{array}{l}\text { Human } \\
\text { cytosolic } \\
\text {.Beta.- } \\
\text { glucosidase }\end{array}$ & $\begin{array}{l}\text { Hydrolyses certain flavonoid } \\
\text { glucosides, with specificity } \\
\text { on the aglycone moiety }\end{array}$ & Bansode et al., (2016) \\
\hline 2 & $3 k 35$ & SIRT6 & $\begin{array}{l}\text { SIRT6 is a member of the } \\
\text { evolutionarily conserved sirtuin family } \\
\text { of NAD(+)-dependent protein } \\
\text { deacetylases and functions in genomic } \\
\text { stability and transcriptional control of } \\
\text { glucose metabolism }\end{array}$ & $\begin{array}{l}\text { Nguyen Vo et al., } \\
\text { (2016) }\end{array}$ \\
\hline 43 & $1 v 4 t$ & Glucokinase & $\begin{array}{l}\text { Glucokinase is a monomeric enzyme } \\
\text { that displays a low affinity for glucose } \\
\text { and a sigmoidal saturation curve for its } \\
\text { substrate, two properties that are } \\
\text { important for its playing the role of a } \\
\text { glucose sensor in pancreas and liver. } \\
\text { Helps in regulation of normal glucose } \\
\text { homeostasis }\end{array}$ & Bansode et al., (2016) \\
\hline 4 & 3W37 & $\begin{array}{l}\text { Sugar beet al., } \\
\text { pha- } \\
\text { glucosidase }\end{array}$ & $\begin{array}{l}\text { A member of glycoside hydrolase } \\
\text { family } 31 \text {, shows exceptional long- } \\
\text { chain specificity, exhibiting higher } \\
\text { kcat/Km values for longer malto- } \\
\text { oligosaccharides }\end{array}$ & Bansode et al., 2016 \\
\hline
\end{tabular}


Table.2 Binding energy of 18 compounds against $\beta$-glucosidase, SIRT6, glucokinase and $\alpha$ glucosidase

\begin{tabular}{|c|c|c|c|c|}
\hline Compound No & $\begin{array}{l}\text { B-glucosidase } \\
\mathrm{kcal} / \mathrm{mol}\end{array}$ & $\begin{array}{l}\text { SIRT6 } \\
\mathrm{kcal} / \mathrm{mol}\end{array}$ & $\begin{array}{l}\text { Glucokinase } \\
\mathrm{kcal} / \mathrm{mol}\end{array}$ & $\begin{array}{l}\alpha \text {-glucosidase } \\
\text { kcal } / \mathrm{mol}\end{array}$ \\
\hline 1 & -79.9253 & -76.1411 & -71.4819 & -70.5395 \\
\hline 2 & -76.2301 & -101.329 & -102.282 & -77.1365 \\
\hline 3 & -69.4915 & -62.8119 & -51.0872 & -53.7303 \\
\hline 4 & -67.6895 & -86.8328 & -79.6515 & -79.7683 \\
\hline 5 & -56.9351 & -61.3696 & -66.8995 & -50.4144 \\
\hline 6 & -56.1988 & -73.172 & -61.2766 & -60.5665 \\
\hline 7 & -63.9731 & -80.1472 & -62.2077 & -67.7164 \\
\hline 8 & -94.0344 & -96.3651 & -93.8057 & -91.2554 \\
\hline 9 & -77.3211 & -76.4698 & -63.4098 & -65.6789 \\
\hline 10 & -80.8739 & -98.9226 & -100.224 & -86.1721 \\
\hline 11 & -73.719 & -76.194 & -72.4426 & -72.6047 \\
\hline 12 & -50.4287 & -61.4115 & -48.2538 & -63.2405 \\
\hline 13 & -82.0591 & -87.0545 & -101.76 & -80.2074 \\
\hline 14 & -81.2129 & -90.1925 & -92.0816 & -88.581 \\
\hline 15 & -66.4611 & -88.3356 & -76.3378 & -70.9528 \\
\hline 16 & -66.1467 & -85.788 & -70.7006 & -69.5932 \\
\hline 17 & -81.3159 & -91.2764 & -79.7921 & -72.0773 \\
\hline 18 & -68.2095 & -75.1987 & -86.024 & -71.515 \\
\hline Acarbose & -113.424 & -120.472 & -122.221 & -121.659 \\
\hline
\end{tabular}

CPD NO: compound No A: Acarbosestandard drug

Table.3 Docking results of Benzeneacetonitrile, .Alpha.-(.Beta.-D-Glucopyranosyloxy)-, (R) against the B-glucosidase, $\alpha$-glucosidase, glucokinase and SIRT6

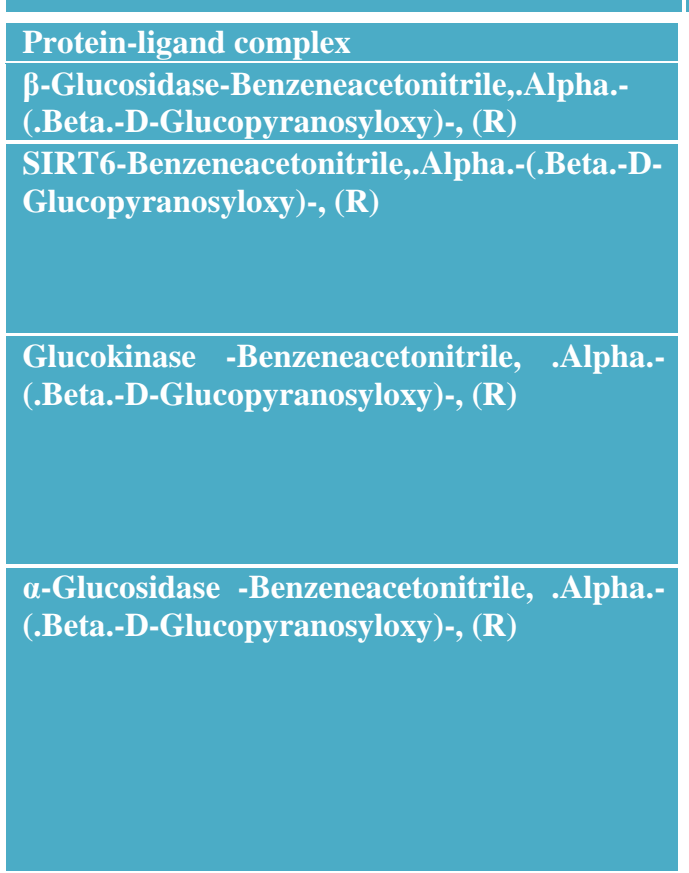

\begin{tabular}{|l|l|}
\hline No of H-bonds & Interaction amino acids \\
\hline 2 & TRP345, NE1---3.1---O20 \\
& GLU424 OE2---3.2---O21 \\
\hline 5 & LEU239 N9---3.5---N \\
GLU20 O21---3.4---OE2 \\
ASP61 O21---3.1---OD2 \\
THR55 O20---3.2---OG1 \\
GLY52 O18---2.9---O \\
\hline 6 & ILE225O18---2.6---O \\
& ASN204 O2O---2.5---OG1 \\
& ASN204 O2O---3.2---N \\
& ASN204 O2O---2.8---ND2 \\
& THR206 O2O---3.3---N \\
& ASP205 O21---2.6---OG1 \\
& ARG699O21---2.8---NH1 \\
& ARG699O21---3.1---NH2 \\
& ARG699 O10---3.1---NH1 \\
& THR790 O21---2.3---OG1 \\
& GLU792O2O---2.7---O \\
& GLU792 O18---2.3---OE2 \\
& ARG814O18---3.3---NH2 \\
& GLY791 N9---2.9---NH1 \\
\hline
\end{tabular}




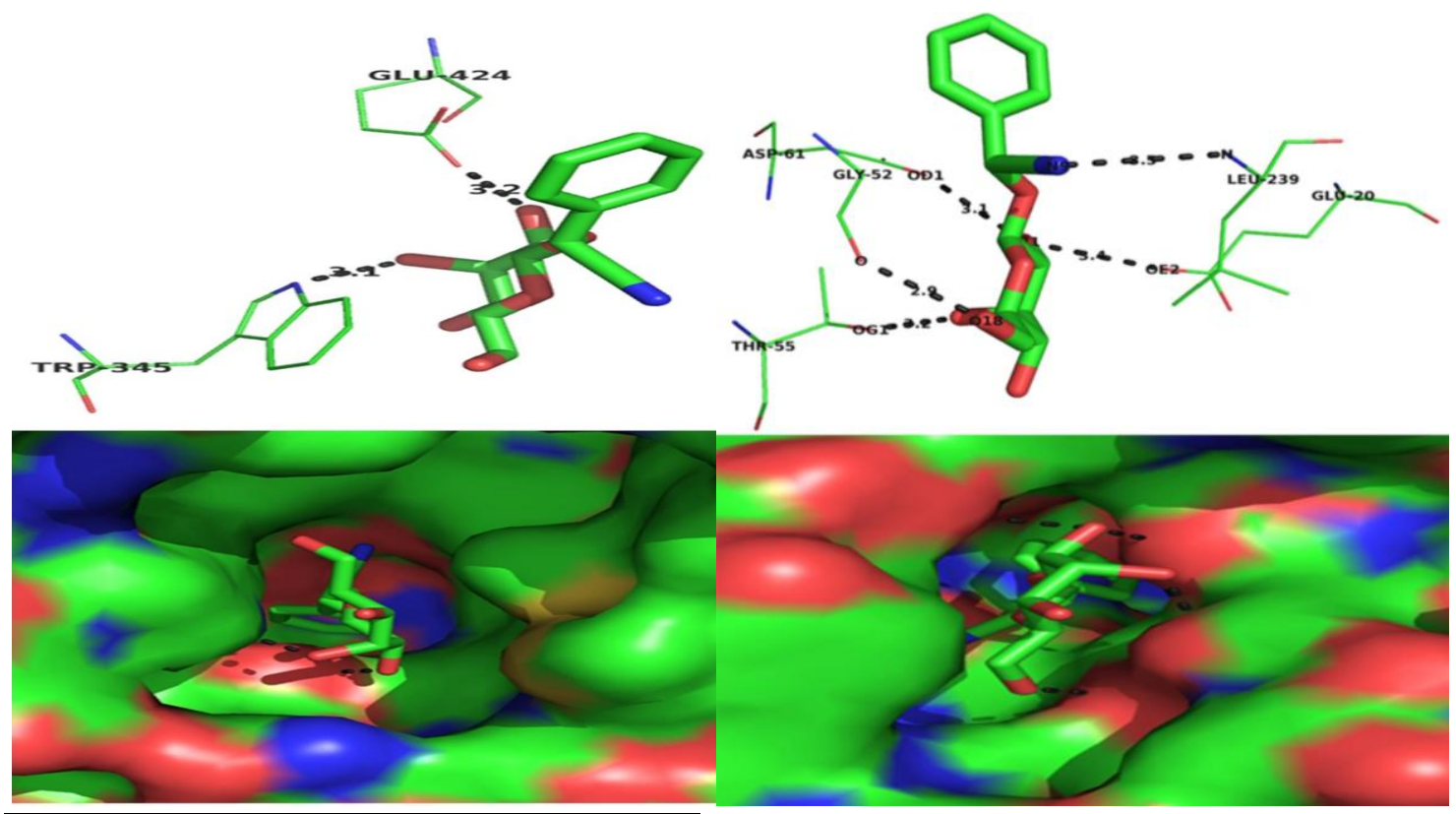

Fig.1 $\beta$-glucosidase interacting With Benzeneacerontrile, .Alpha. -(.Beta.-DGlucopyranosyloxy)-,(R)

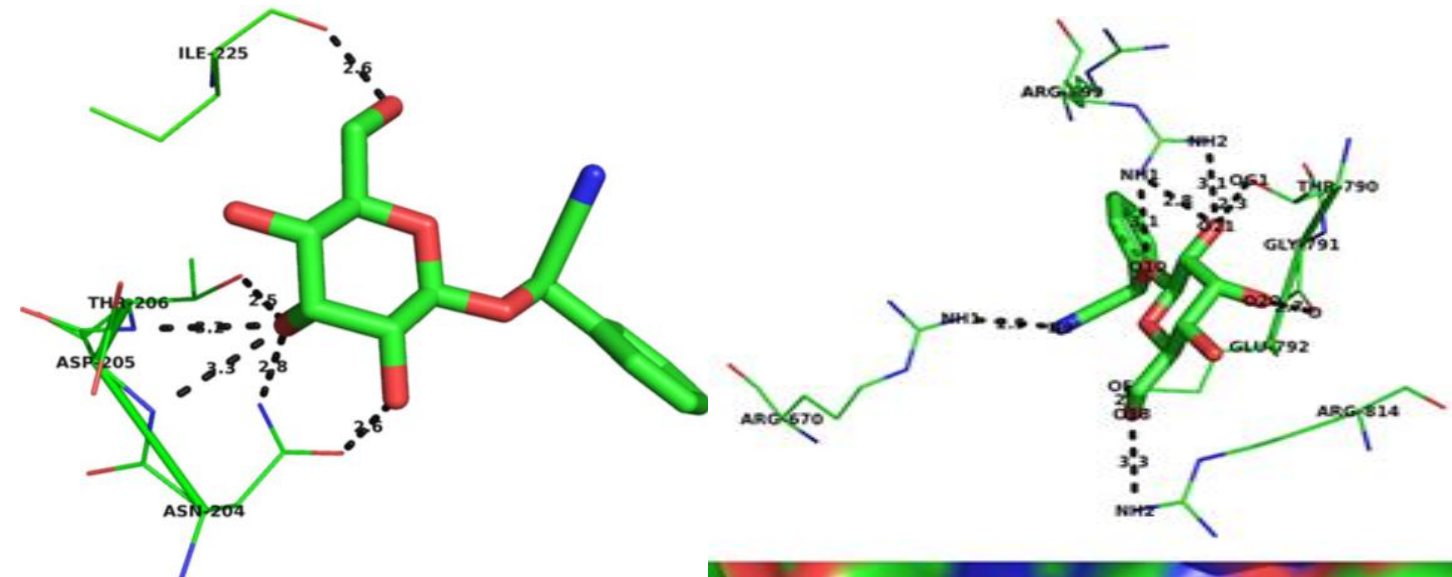

Fig.2 SIRT6 interacting With Benzeneacerontrile, .Alpha. -(.Beta.-DGlucopyranosyloxy)-,(R)

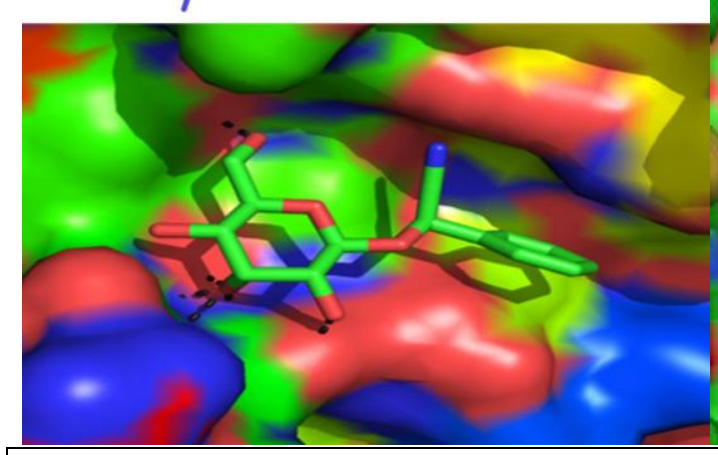

Fig.3 Glucokinase interacting With Benzeneacerontrile, .Alpha. -(.Beta.-DGlucopyranosyloxy)-,(R)

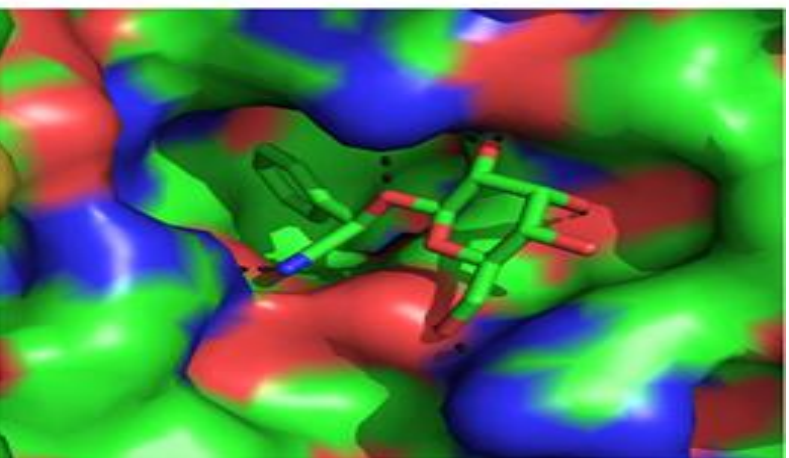

Fig.4 $\alpha$-glucosidase interacting With Benzeneacerontrile, .Alpha. -(.Beta.-DGlucopyranosyloxy)-,(R) 
Benzeneacetonitrile,

.Alpha.-(.Beta.-D-

Glucopyranosyloxy)-, (R) interacting with diabetic with best binding energy.

Its detailed interaction like amino acid residues, no of hydrogen bond were in given in Table 2 and interaction between protein and ligands were showed in Figure 1, 2, 3 and 4.

Several years required for developing drug and to introduce in market requires huge amount. According to kennedy et al., (1997) most of drugs in development phase at final stage fail in clinical trials due to toxicity or poor pharmacokinetics properties it create a huge loss to pharmaceutical company.

Bio informatics tools provide a great support to pharmaceutical company in drug discovery in short duration time with less cost all primary information can be obtain before going to in vitro and in vivo studies (Liu et al., 2013). Five proteins were selected from literature survey $\beta$-glucosidase, $\alpha$-glucosidase, are enzymes and glucokinase, SIRT6 are protein responsible for diabetic.

Inhibiting this protein will reduce glucose level in blood. Our results are similar with Rathore et al., (2016) findings Gymnemagenin interact with glucokinase residues are THR82/OG1, ASN83/O, THR228/OG1, SER441/O AND GLU443/N.

In structure based drug design protein ligand interaction plays a critical role. Our present study focus on identification of antidiabetic phytochemical present in $S$. reticulate by using iGem dock against $\beta$-glucosidase, $\alpha$ glucosidase, SIRT6, glucokinase. Benzeneacetonitrile, .Alpha.-(.Beta.-DGlucopyranosyloxy)-, (R) - is compound found in $S$. reticulata may response for antidiabetic activity future validation can be done by isolating the Chemical and in vitro antidiabetic.

\section{References}

Abirami $\mathrm{N}$ and Arulmozhi. R.In-Silico Approach Towards Protein Targets Related to Diabetes Mellitus-An Overview. Orient. J. Chem., 2017, 33(4), 1614-1622.

Balavignesh V, Srinivasan E, Ramesh Babu NG. Molecular docking study ON NS5B polymerase of hepatitis c virus by screening of volatile compounds from Acacia concinna and ADMET prediction. International Journal of Pharmacy \& Life Sciences. 2013; 4(4): 2548-2558.

Hoang Nguyen Vo, T., Ngan Tran, Dat Nguyen and Ly Le, An in silico study on antidiabetic activity of bioactive compounds in Euphorbia thymifolia Linn. Springer Plus 2016. 5:1359.

Lill M A, Danielson M L. computer aideddrug design platform using PyMoL. J. computer aided molecular discovery. 2010. 25:13-19

Matsuda H, Yoshikawa, M, Morikawa T, Tanabe $\mathrm{G}$ and Muraoka, O. Antidiabetogenic constituents from Salacia species. Journal of traditional medicine. 2005, 22(1): 145-153.

Neema T, Kumud P, Bhasker P.Docking studies of grayanotoxin as potential inhibitor for major virulent proteins of encephalitis virus. Int. J. Pharmtechres, 2015, 7(1), 156-164.

Ntie-Kang et al., 2013. In silico drug metabolism and pharmacokinetic profiles of natural products from medicinal plants in the Congo basin. In Silico Pharmacology 2013 1:12.

Pratibha P, Sophia D, Perumal P C and Gopalakrishnan KV. In-silico docking analysis of Emilia sonchifolia (L.) Dc.gas chromatography-mass spectroscopy derived terpenoid compounds against pancreatic cancer targets (akt and brca2). World journal of 
Pharmacy and Pharmaceutical Sciences. 2014, 3(6), 1844-1855.

Rathore PK, Arathy V, Attimard VS, Kumar $\mathrm{P}$ and Roy S. In-silico analysis of gymnemagenin from Gymnemasylvestre (Retz.) R.Br. with targets related to diabetes. Journal of Theoretical Biology. 2016, 391.95-101.

Twinkle S. Bansode, Amit Gupta, Sushama Chaphalkar and B. K. Salalkar. Integrating In-silico and In-vitro
Approaches to Screen the Antidiabetic Drug from Trigonella foenumgraecum Linn. International Journal of Biochemistry Research \& Review, 2016, 14(3): XX-XX.

Wesam Kooti, Maryam Farokhipour, Zahra Asadzadeh, Damoon Ashtary-Larky, Majid Asadi-Samani. The role of medicinal plants in the treatment of diabetes: a systematic review. Electron Physician. 2016 Jan; 8(1): 1832-1842.

\section{How to cite this article:}

Ramakrishna, D., A.T. Shashank, S. Kiran, K.M. Kumar and Ravishankar, G.A. 2018. In silico Identification of Inhibitors from Salacia reticulata Plant against Diabetic Target Protein. Int.J.Curr.Microbiol.App.Sci. 7(01): 431-438. doi: https://doi.org/10.20546/ijcmas.2018.701.050 